\title{
Pedro Henríquez Ureña Profesor en México
}

H. $\mathrm{N}$ el año de 1913, Pedro Henríquez Ureña era profesor de C] literatura castellana en la Escuela Nacional Preparatoria. Las mismas enseñanzas impartía el gran poeta Luis G. Urbina. Pedro con él había compartido la redacción de la Antología del Centenario, obra excelente que estudia la producción literaria de México en los primeros diez años de su vida independiente. La obra se proponía abarcar el estudio de la literatura mexicana en los años comprendidos de 1810 a 1910. La revolución iniciada en este último año dejó trunca la obra que prometía ser fundamental para el conocimiento de la obra de poetas y prosistas en el primer siglo de México como nación desvinculada de España. Henríquez Ureña aportaba a este propósito, iniciado y fomentado por el entonces Ministro de Instrucción Pública, don Justo Sierra y secundado por Nicolás Rangel, el eminente historiador, además de los dos ya citados hombres de letras, su erudición, su buen gusto, su conocimiento de las letras mexicanas.

En la cátedra de Henríquez Ureña no sólo se aprendía a conocer a los autores españoles, sino también a investigar. Se adquiría una disciplina intelectual que ha servido de mucho a los que después se han dedicado al cultivo de las disciplinas literarias. No era un brillante expositor, no tenía la elocuencia de don Antonio Caso por ejemplo, pero sí sabía encontrar la vocación de sus discípulos y la sabía encauzar. Era un buen partero de almas como quería Sócrates para los maestros. Formó así un grupo importante de discípulos. De entre ellos sur- 
gió una publicación que hasta ahora se consulta con provecho: Las cien mejores poesias de la literatura mexicana reunidas por Antonio Castro Leal, Manuel Toussaint y Alberto Vázquez del Mercado.

Henríquez Ureña formaba parte del grupo conocido con el nombre de "Generación del Ateneo". Fue miembro fundador de la Sociedad de Conferencias que había de dar origen al "Ateneo de la Juventud". Los que la integraban habían de dar en su mayoría lustre y decoro a las letras mexicanas. La generación del Ateneo se había de distinguir por la preferencia dada a los estudios filosóficos y al ensayo como expresión. Fue menos lírica que la que actuó bajo el signo del Modernismo. Trató de ir más allá del positivismo, que había sido la doctrina oficial de la República desde 1868. Para ello era menester que sus componentes contemplaran el panorama del mundo intelectual contemporáneo. La Universidad reabierta por don Justo Sierra en 1910 necesitaba de la cooperación de estos jóvenes que se dedicaron en cuerpo y alma a la renovación del ambiente del México de entonces. Pedro Henríquez Ureña aportó en ello su sabiduría, su curiosidad siempre despierta, su inteligencia lúcida y su capacidad de trabajo. Reconocieron su autoridad compañeros suyos que han dejado honda huella en la vida intelectual de México: Antonio Caso, José Vasconcelos, Alfonso Reyes, Carlos González Peña, Julio Torri.

Creada la Faciltad de Altos Estudios en la recién formada Universidad, Henríquez Ureña enseñó Literatura Castellana, primero y Literatura Comparada después, formando en ambas cátedras a los estudiantes que habían de sustituirlo más tarde en la enseñanza.

Cuando se trató de superar la doctrina positivista que era el alma de la enseñanza superior en el México de entonces, Henríquez Ureña cooperó con el Ministro de Educación don Nemesio García Naranjo para abrir las ventanas de la Escuela Nacional Preparatoria a horizontes nuevos. Se reformó el plan de esa Escuela incorporando en él los estudios de los problemas de Filosofía que habían estado ausentes de él, los de Arte que no habían aparecido en el curriculum de la enseñanza superior. Se incorporó la Literatura Mexicana. Se pretendió que las Humanidades tuvieran el lugar que les co- 
rresponde en la enseñanza. Desgraciadamente la caída del régimen hizo que el plan de estudios fuera flor de un día. El viaje al extranjero de Pedro Henríquez Ureña interrumpió su enseñanza en la Universidad. Dejaba ya varias publicaciones importantes: Horas de estudio y sus Tablas cronológicas de la Literatura Castellana. Había colaborado en las revistas mexicanas de mayor importancia. En una de ellas se publicó su importante estudio sobre el Maestro Hernán Pérez de Oliva, que presenta un panorama muy rico del Renacimiento Español. En el año de 1914 pronuncia su conferencia sobre Juan Ruiz de Alarcón que marca época en los estudios sobre la dramática del gran autor mexicano.

Al asumir la Rectoría de la Universidad primero y la Secretaría de Educación después, don José Vasconcelos en el año de 1920, Pedro Henríquez Ureña vuelve a México, para fundar la Escuela de Verano, que tanta importancia ha tenido para el conocimiento de México en los Estados Unidos particularmente. Se rodea de un profesorado capaz y entusiasta. Incorpora a sus discípulos a la enseñanza. Implanta nuevos métodos en la docencia y en la investigación universitaria. En la Escuela de Altos Estudios, ahora Facultad de Filosofía y Letras, inicia un seminario de letras españolas, uno de los primeros cursos de este tipo que se dieron en la Universidad. Sigue desempeñando su cátedra de Literatura Comparada.

En el año de 1923 va a Puebla a ocupar la dirección de la educación pública del Estado. Los tiempos son difíciles. E1 país está en plena agitación por el movimiento de la Huertista. $\mathrm{Su}$ paso por ese puesto es fugaz. Tiene que salir del país. Encuentra ocupación en las Universidades de Buenos Aires y de La Plata.

Fuí discípulo de Pedro Henríquez Ureña en 1914 y en 1921 y 1922. Su enseñanza dejó en mí hondas huellas. Me enseñó a trabajar en la investigación de temas literarios. Cooperé con él como maestro en la Escuela de Verano y seguí sus huellas como Director de este Instituto en 1928. Le sucedí en la cátedra de literatura española en la Facultad de Altos Estudios cuando salió del país. Soy, pues, testigo de la importancia de la obra realizada por el maestro dominicano en nuestro país. Seguí correspondiendo con él desde México y a 
veces desde el extranjero. Sus cartas traían siempre una enseñanza, un consejo, una observación certera y útil. Después de diez años de su tránsito sigo considerándolo como uno de los maestros más esclarecidos de Iberoamérica.

JULIO JIMÉNEZ RUEDA.

Universidad Nacional

Autónoma de México 